\title{
Recurrent hypercalcaemia in a young man with mono-ostotic Paget's disease
}

\author{
P. Bannister ${ }^{1}$, M. Roberts ${ }^{2}$ and P. Sheridan ${ }^{2}$ \\ Departments of Medicine, ${ }^{1}$ St. James's University Hospital, Leeds LS9 7TE and ${ }^{2}$ Seacroft Hospital, Leeds 14, UK
}

\begin{abstract}
Summary: A 32 year old man presented on two separate occasions with severe hypercalcaemia. Both episodes followed the fracture of a single pagetic bone but were not associated with immobilization. To our knowledge this patient, the youngest described with hypercalcaemia secondary to Paget's disease of bone is also the only reported case of recurrent hypercalcaemia in this condition.
\end{abstract}

\section{Introduction}

Hypercalcaemia is an uncommon complication of Paget's disease. Well documented cases are rare but it is usually associated with widespread disease in the elderly immobilized patient often with an associated fracture (Reifenstein \& Albright, 1944; Fuss et al., 1978; Nathan et al., 1982). We describe recurrent hypercalcaemia in a 32 year old man with monoostotic Paget's disease.

\section{Case report}

The patient first came to medical attention aged 16 with deformity and discomfort of the right shin. X-ray investigation and isotope bone scan showed monoostotic Paget's disease of the right tibia; the diagnosis was confirmed by bone biopsy when aged 23 . He was well until 6 weeks before admission when, aged 32, he fractured his right tibia, which was immobilized in plaster of paris. One week before admission he noted anorexia, nausea and vomiting which progressively worsened. He remained ambulant throughout this period with the aid of crutches and a walking plaster.

On admission he was unwell and complained of abdominal pain. He was dehydrated but physical examination was otherwise normal. Biochemical investigation showed renal impairment, plasma urea $20.6 \mathrm{mmol} / 1$ (normal range $2-8 \mathrm{mmol} / \mathrm{l}$ ), plasma creatinine $361 \mu \mathrm{mol} / 1$ (normal $45-120 \mu \mathrm{mol} / \mathrm{l}$ ) and marked hypercalcaemia, plasma calcium $3.88 \mathrm{mmol} / 1$ (normal 2.2-2.6 mmol/l) with a normal albumin $42 \mathrm{~g} / 1$ (normal 37-49 $\mathrm{g} / \mathrm{l}$ ) and a moderately raised plasma phosphate, $1.58 \mathrm{mmol} / 1$ (normal $0.8-1.3 \mathrm{mmol} / \mathrm{l}$ ); urine hydroxyproline excretion was raised, $0.61 \mathrm{mmol} /$

Correspondence: P. Bannister, M.B., M.R.C.P.

Accepted: 20 November 1985
24 hours (normal $0.11-0.33$ ). He was treated with intravenous $0.9 \%$ saline, frusemide, and oral prednisolone for $\mathbf{4 8}$ hours and then with salmon calcitonin 300 IU twice daily. His hypercalcaemia and renal failure resolved over the next 7 days (Figure 1).

Further investigation excluded primary hyperparathyroidism; plasma parathyroid hormone levels were undetectable, plasma phosphate returned to within the normal range and the tubular maximal reabsorption of phosphate (TMP/GFR) was normal during the hyper- and normocalcaemic phases of his illness. Independent assessment of his previous X-rays and bone biopsy confirmed the diagnosis of Paget's disease. He was discharged home taking salmon calcitonin 3 times a week for 3 months. His fracture healed and he remained well and normocalcaemic over the next 12 months.

Sixteen months after the first admission he again fractured his right tibia. This fracture was treated by external fixation (Figure 2) and full mobility was maintained. Two weeks after the fracture he again noticed nausea and vomiting. Investigation confirmed hypercalcaemia (plasma calcium $3.3 \mathrm{mmol} / \mathrm{l}$ ) but renal function was normal. The hypercalcaemia responded to the same therapy, but he was maintained on salmon calcitonin for 6 months. At outpatient review one year after the second fracture he remains well, mobile and normocalcaemic. Subsequently an isotope bone scan has confirmed the mono-ostotic nature of the patient's Paget's disease.

\section{Discussion}

This case is the first description of recurrent hypercalcaemia in Paget's disease. Hypercalcaemia in Paget's disease, without concurrent hyperparathyroidism is 


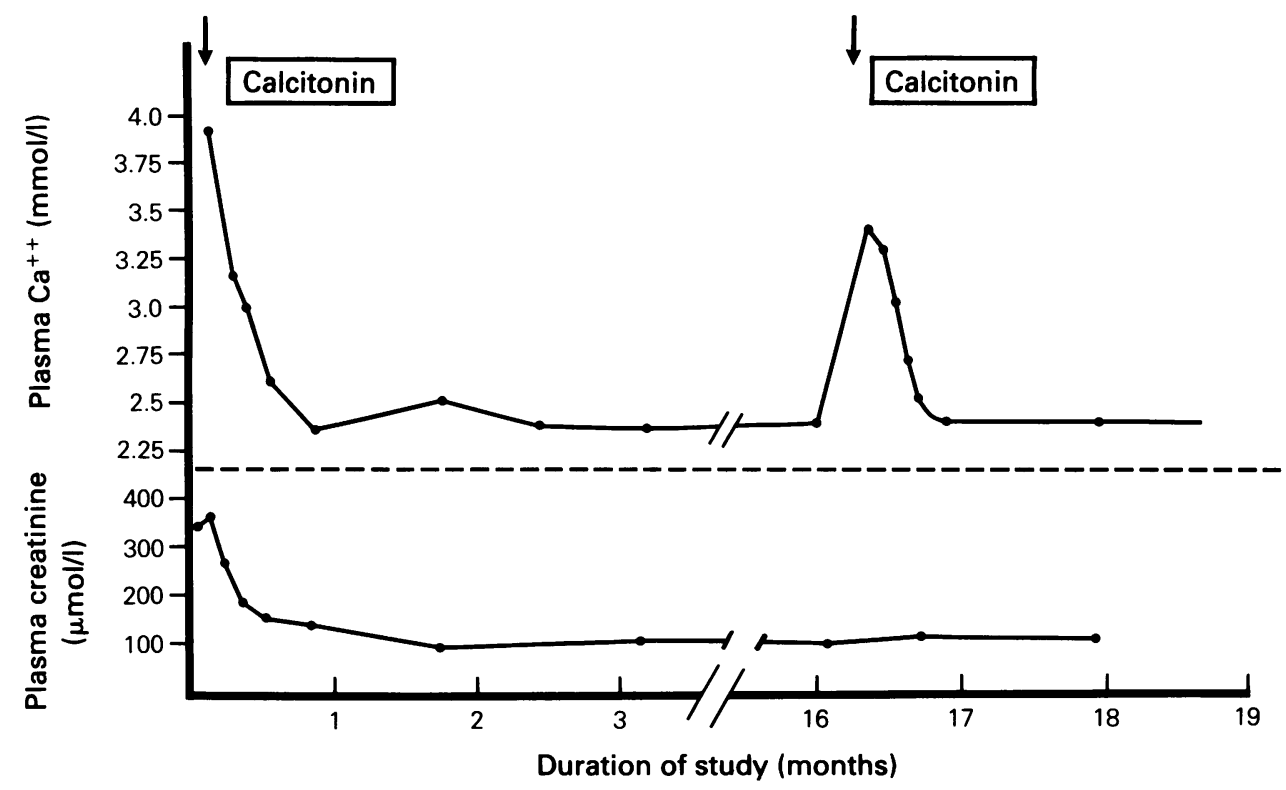

Figure 1 Serum calcium and creatinine levels during both the hyper calcaemic and recovery phases of the subjects' illness. The arrows indicate the times of the 2 tibial fractures.

rare. The 6 cases documented in the literature (Fuss $e t$ al., 1978; Auld et al., 1979; Nathan et al., 1982) occurred in much older, immobilized patients with widespread disease. In 4 of the cases there was an associated fracture and of these 3 had had drug treatment or diet which could have contributed to the hypercalcaemia. The hypercalcaemia in these cases was attributed to increased mobilization of bone calcium with associated increased renal absorption. A similar pattern of 'resorptive immobilization hyper- calcaemia' is also described in young people after prolonged bed rest (Stewart et al., 1982) but is not 8 associated with the relatively mobile patient. Presumably the mobilization of calcium from a single fractured and immobilized pagetic bone in this patient was sufficient to induce hypercalcaemia.

The case is also of interest in view of the patient's age. $\mathrm{He}$ is the youngest patient described to our knowledge, with hypercalcaemia in Paget's disease in addition is the second youngest patient described

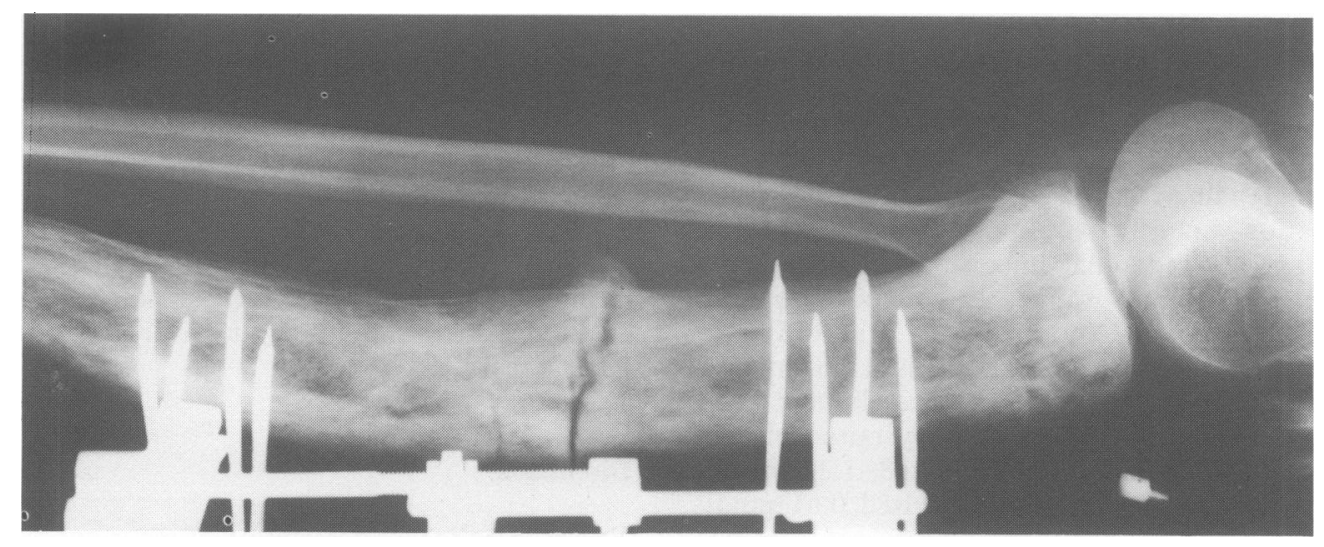

Figure 2 Lateral radiograph of the right tibia showing severe Paget's disease and a transverse fracture with external fixation. 
with histologically proven Paget's disease. From our review of other published work, Wagner (1947) described an 18 year old who was studied in detail but most other cases are incidental radiological or postmortem findings or in extreme youth they represent 'juvenile Paget's disease'. This condition is a misnomer: it has histology differing from adult Paget's disease, always affects multiple sites and probably represents part of the spectrum of inherited metabolic bone disease (Jacobs, 1972).

Thus, severe hypercalcaemia can occur in the relatively mobile young patient if a single diseased bone

\section{References}

AULD, W.H.R., SIMPSON, R.H. \& SMYTH, M. (1979). Hypercalcaemia in Paget's disease of bone. Lancet, i, 562 .

FUSS, M., BERGANS, A. \& CORVILIAN, J. (1978). Hypercalcaemia due to immobilisation in Paget's disease of bone. Lancet, ii, 941.

GILLESPIE, W.J. (1979). Hypercalcaemia in Paget's disease of bone. Australian and New Zealand Journal of Surgery, 49, 84

JACOBS, P. (1972). Paget's disease in a five year old. British Medical Journal, $2,614$.

NATHAN, A.W., LUDLAM, H.A., WILSON, D.W. \& DANDONA, P. (1972). Hypercalcaemia due to immobilisation of a patient with Paget's disease of bone. Postgraduate Medical Journal, 58, 714. is immobilized. However hyperparathyroidism must be excluded for concomitant parathyroid adenomas and hypercalcaemia have been described in an immobilized patient with Paget's disease (Gillespie, 1979).

\section{Acknowledgements}

We are grateful to Professor R.A. Dickson in allowing us to report on this patient.

REIFENSTEIN, E.C. \& ALBRIGHT, F. (1944). Paget's disease: it's pathologic physiology and the importance of this in the complications arising from fracture and immobilisation. New England Journal of Medicine, 231, 343.

STEWART, A.F., ADLER, M., BYERS, C.M., SEGNE, G.V. \& BROADUS, A.E. (1982). Calcium homeostasis in immobilisation: an example of resorptive hypercalcuria. New England Journal of Medicine, 306, 1136.

WAGNER, M. (1947). Report of a case of Paget's disease in an 18 year old male, with a review of the literature. Wisconsin Medical Journal, 46, 1098. 